\title{
The Use of Intelligent Microprocessor Modules for Working with Sound Communication in the Development of Educational Equipment
}

\author{
Volodymyr Kartashov \\ ORCID 0000-0001-8335-5373 \\ Department of Natural Sciences \\ Kharkiv National University of Radio Electronics \\ Kharkiv, Ukraine \\ volodymyr.kartashov@nure.ua
}

\author{
Roman Tsekhmistro \\ ORCID 0000-0003-3628-3658 \\ Department of MIRES \\ Kharkiv National University of Radio Electronics \\ Kharkiv, Ukraine \\ tsekhmistroroman@gmail.com
}

\begin{abstract}
This report is devoted to an overview of the technical characteristics and the specifics of the application of modern debugging microprocessor modules for recognizing audio and text signals.
\end{abstract}

Keywords-microcontroller system, RAM memory, EEPROM memory, $R S C-4128$ speech recognition processor

\section{INTRODUCTION}

The success of modern technologies has made it possible to create intelligent microprocessor-based speech and sound recognition modules with built-in MEMS micro-phones and with traditional microphones that are connected. One of these modules is shown in Fig.1. It includes 4 microphones created using MEMS technology.

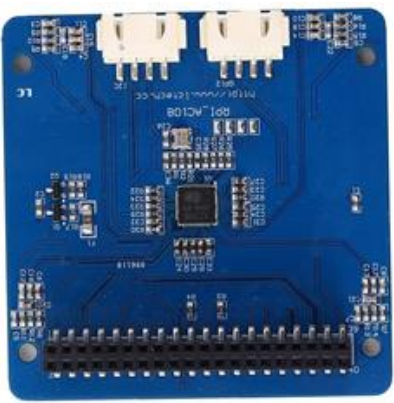

Fig. 1. Voice recognition module AC-108

Fig. 2 shows a plug-in microphone module. These appliances can be used in industrial devices. [1-2].

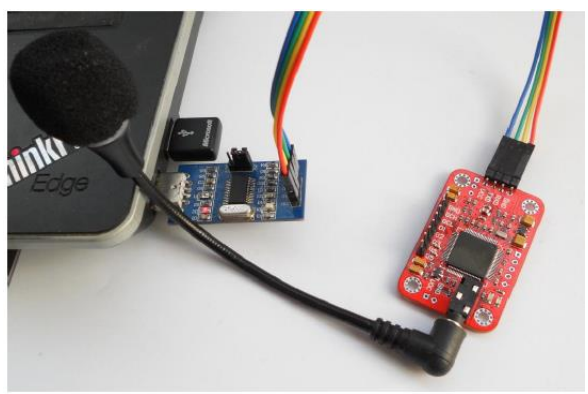

Fig. 2. Voice recognition module V3.1 Elechouse
It has the following parameters: input memory can record 80 seconds sound voice of beep and put in EEPROM memory (storage without power supply). Before recognizing voice commands, they must be loaded from the storage memory (EEPROM) into the recognizer memory. RAM memory - the operative recognizer is designed for 7 voice commands, which means the module is able to simultaneously compare up to 7 voice commands with the incoming sound signal.

The module shown in Fig. 1 uses the RASPBERRY PI 40PIN interface, suitable for motherboards of the RASPBERRY PI series. There are 12 programmable fullcolor LEDs APA-102-2020 on the module board.

Raspberry Pi control interface: I2C, audio interface: I2S, Raspberry Pi drives the microphone array to capture voice via $\mathrm{I} 2 \mathrm{C}$ interface, and then transmits the voice signal to the Raspberry $\mathrm{Pi}$ via $\mathrm{I} 2 \mathrm{~S}$ interface and finally $3.5 \mathrm{~mm}$ headphones. basic / interface HDMI audio output.

The audio-wm8960 sound recognition module is shown in the Fig. 3.

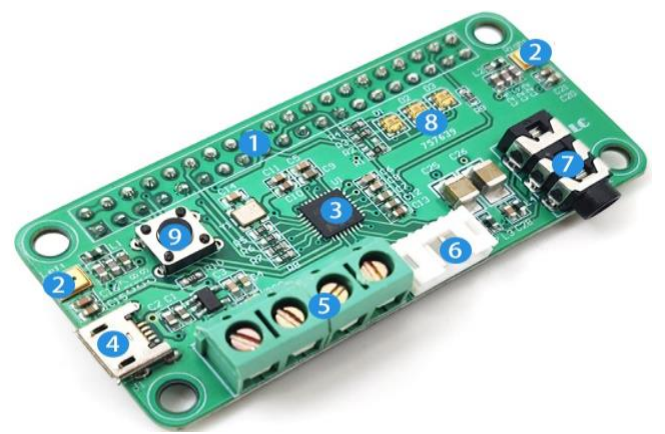

Fig. 3. Voice recognition WM8960

1) Communication interface with minicomputer RASPBERRY Pi.

2) Levi and right MEMS microphone;

3) WM8960: low-power stereo codec;

4) Additional power. If the output is connected to a microphone, this micro USB provides sufficient current;

5) KF301-4P - left and right output channel of the speaker, pressure $2 \times 1 \mathrm{~W}$; 
6) РН2.0-4П: left and right output channel speaker, pressure $2 \mathrm{x} 1 \mathrm{~W}$;

7) Output to the headphones: pressure $40 \mathrm{MW}$ (16 Ohm, $3.3 \mathrm{~V})$;

8) RGB LED: 3 APA102 color-coded LEDs, connected to SPI interface for Ruspberry Pi.

\section{MAIN PARTS}

Consider further the ELECHOUSE V3 recognition module based on the RSC-4128 sound processor, since it has a removable microphone, which makes it possible to expand the practical aspects of its use [3-4]. In addition, there is information about the characteristics of this microphone:

- sensitivity: $-38 \mathrm{~dB}$

- load impedance: $2.2 \mathrm{kOhm}$;

- $\quad$ supply voltage: $3 \mathrm{~V}$;

- frequency response: $100 \mathrm{~Hz}$ to $20 \mathrm{kHz}$.

The module is able to work without an external microcontroller, since the manufacturer has laid down functional independence, it is only necessary to record voice commands once and set the settings for independent operation using an external device (PC or MK).

To start working with the voice recognition module, we need to connect it either to a computer (we need a USBUART connector Fig. 2), or to a microcontroller. If a microcontroller is used, it is necessary to develop a program code to control the module.

The principle of sound recording is associated with fast Fourier transform, creates an array of frequencies from time and then compares the input data with the available arrays. To train the module, the scheme shown in Fig. 2 is used. For the training process, a terminal program (Fig. 4) and instructions (commands) from the datasheet are used.

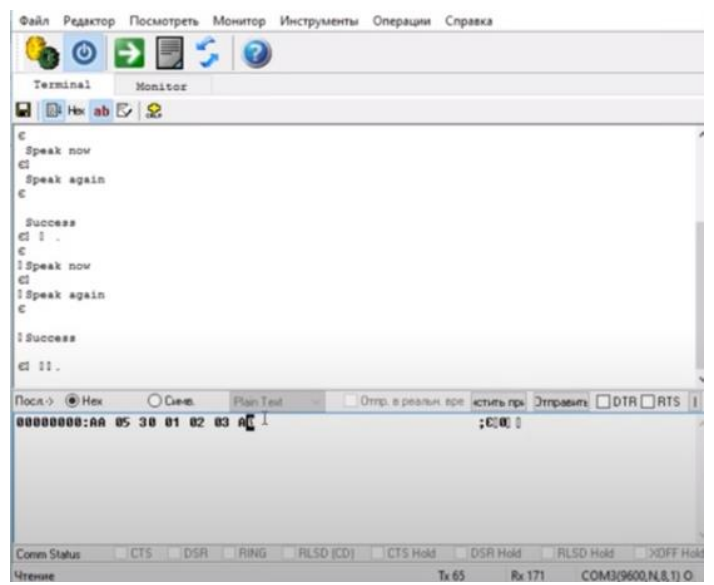

Fig. 4. Application will write commands to module V3 c using the terminal program

Fig. 2 shows that 4 pins (IN0, IN1, IN2, GND) can be used to input the required groups of voice commands from storage into the voice command recognizer [3]. In order for the module to start recognizing voice commands after turning off and turning on the power, you need to specify which voice commands are required to be automatically loaded from the storage into the recognizer when power is applied. The OUT-0 ... .6 pins are designed to record the fact of recognition. It reacts to the recognition of the voice command in the 0-6 cell of the recognition device [3] RSC4128 Overview presented Fig.5.

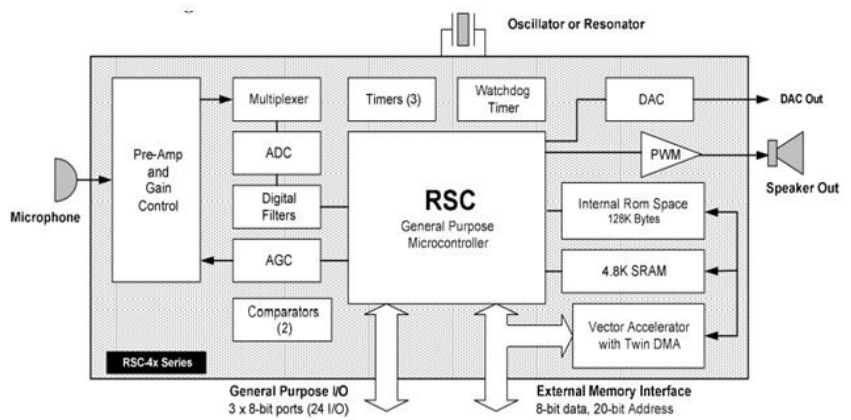

Fig. 5. Structura signal proseccor RSC-4128

The RSC-4128 operates in tandem with FluentChip firmware, an ultra compact suite of recognition and synthesis technologies [4]. The CPU core embedded in the RSC-4128 is an 8-bit, variable-length-instruction micro-controller. The instruction set is similar to 8051 microcontroller, and has a variety of addressing mode, mov and 16 bit instructions.

The RSC-4128 has a high frequency (14,32 MHZ) clock as well as a low $(32,768 \mathrm{~Hz})$ clock. The RSC-4128 128 kbytes ROM, 16 bit ADC, 10bit DAC and micro-phone.

\section{CONCLUSIONS}

A brief overview of the specifications of the specified microprocessor devices gives an opportunity for developers of experimental (exclusion) projects both scientific and industrial purpose to save time for development of the product.

Small overall dimensions and low energy consumption allows to actively use the designed module in projects type "Smart house" and others.

This fact is especially relevant because the modules are software and hardware compatible with the popular "Arduino" and "Rassberry " microcontrollers.

\section{REFERENCES}

[1] M.A. Omarov, R.I. Tsekhmistro "Avtomatyzovana systema vidboru i teploviziyna diahnostika nezhyttyezdatnykh embrioniv $\mathrm{v}$ period inkubatsiyi yayets' sil'skohospodars'koyi ptytsi,“ Zbirnyk prats' II Mizhnarodnoyi konferentsiyi vyrobnytstvo y mekhatronni systemy..Kharkov, KHNURE, P. 35-38, 25-26 october, 2018.

[2] Murad Omarov, Vladimir Kartashov, Roman Tsekhmistro. Features of the Use of Microprocessors in the Systems of Ovojectors in their Adaptation to the Conditions of the Former CIS. Theoretical and Applied Aspects of Device Development on Microcontrollers and FPGAs, MC\&FPGA. - 2019. - P. 33-34. doi: 10.35598/mcfpga.2019.012

[3] Voice Recognition Module V3 [Online]. Available: http:// www elechouse.com /elechouse/images/product/VR3/ manual.pdf [Accessed: 1- Jun- 2021]

[4] Speech recording [Online]. Available: https://www.sensory.com/wpcontent/uploads/80-0225-C.pdf [Accessed: 1 - Jun- 2021] 